\title{
Factors associated with severe preeclampsia and eclampsia in Jahun, Nigeria
}

This article was published in the following Dove Press journal:

International Journal of Women's Health

17 August 2013

Number of times this article has been viewed

\author{
Gilles Guerrier' \\ Bukola Oluyide ${ }^{2}$ \\ Maria Keramarou' \\ Rebecca F Grais' \\ 'Epicentre, Paris, France; ${ }^{2}$ Médecins \\ Sans Frontières, Paris, France
}

Correspondence: Gilles Guerrier Epicentre-MSF, 8 rue Saint Sabin, 750II Paris, France

Tel +33 I40 2l 2929

Email guerriergilles@gmail.com
Objective: To explore traditional herbal medicines as potential risk factors of severe preeclampsia and eclampsia in Nigeria.

Methods: We conducted a retrospective case-control study from October 2010 to May 2011. The cases were all pregnant women admitted to the Jahun Hospital during the study period with severe preeclampsia or eclampsia and women presenting with normal pregnancy after 22 weeks.

Results: During the study period, a total of 1,257 women (44\%) were recorded as having normal pregnancy, and $419(16 \%)$ women had severe preeclampsia/eclampsia (175 with severe preeclampsia and 244 with eclampsia). The risk factors found to be associated with a greater risk of severe preeclampsia/eclampsia included personal history of preeclampsia (odds ratio $[\mathrm{OR}]=21.5 ; P<0.001)$, personal history of preexisting hypertension $(\mathrm{OR}=10.5 ; P<0.001)$, primiparity $(\mathrm{OR}=2.5 ; P=0.001)$, occupation as housewife $(\mathrm{OR}=1.9 ; P=0.008)$, and fewer than four antenatal care visits $(\mathrm{OR}=1.6 ; P=0.02)$. Use of traditional treatments during pregnancy was associated with a higher risk of developing severe preeclampsia/eclampsia $(\mathrm{OR}=1.6$ 95\%; confidence interval [CI]: 1.2-2.1) by univariate analysis only.

Conclusion: Use of traditional treatment, which increases delays before consulting the official health sector, might be a marker for harmful behavior. Community-based studies could provide additional information on the practice of herbal therapy in this population.

Keywords: hypertensive disorders, pregnancy, traditional treatments, herbal use

\section{Introduction}

Most of maternal deaths are due to obstetric emergencies, including hemorrhage, sepsis, obstructed labor, and hypertensive disorders, ${ }^{1,2}$ with eclampsia being the leading cause of maternal and perinatal mortality reported in Nigeria over the last decade. ${ }^{3}$ In addition, preeclampsia and eclampsia are major causes of fetal mortality. ${ }^{4}$ The etiology of preeclampsia remains unclear despite extensive research.

It is noteworthy that the use of herbal medicines is widespread among pregnant women in Nigeria, ${ }^{5-7}$ where the legislation for distribution and purchase of herbal remedies is not as stringent as it is for conventional medicines. In this country, the prevalence of herbal remedy use during pregnancy ranges from $12 \%{ }^{7}$ to $67 \%{ }^{5}$ The reasons cited by pregnant women for taking herbal medicines include perceived higher efficacy, easier access and lower cost compared with conventional medicines, safety in pregnancy, and beliefs concerning the cultural heritage of herbal remedies. ${ }^{5}$ However, side effects and the teratogenic potential of most herbal products are poorly understood. A recent study performed in Nigeria found a strong association between self-medication, including herbal use, and hypertension in pregnancy. ${ }^{8}$ 
An emergency obstetric and neonatal care program, operated by Médecins Sans Frontières, has been operating in Jahun, a town in the Jahun Local Government Area in Jigawa State, Nigeria, as part of a comprehensive obstetric package since July 2008. The catchment area that the Jahun hospital serves is 380,000 persons (combining the Jahun and Miga Local Government Areas). The main objective of the program is to decrease maternal and neonatal mortality among those presenting at the Jahun hospital, by addressing the health seeking behavior of women with complications during pregnancy and delivery, the access to health structures, and the quality of care provided at the emergency obstetric and neonatal care program. The current capacity of the hospital is a 41-bed ward (35 standard beds and six intensive care unit beds), staffed with seven midwives (trained to manage labor and delivery and to assist newborns) and four nurse assistants (trained to assist mothers and help midwives) per shift. A recently created neonatal care unit includes resuscitation. A recent analysis of the activity showed that more than $70 \%$ of admissions were complicated deliveries, with a seasonal trend of admissions (217 in January and 413 in August). A surprisingly high number of patients with hypertension as a complication of pregnancy were noted, several of whom were diagnosed with preeclampsia or eclampsia ( $4 \%$ of patients presented with eclampsia compared with the $1 \%$ of eclamptic disorder predicted according to the World Health Organization [WHO] standards). ${ }^{9}$ Typically, the presentation was that of pregnant women after 20 weeks gestational age, arriving in the maternity unit with a history of "Jijjiga," which is the local language (Hausa) term for seizures. This study was undertaken to describe the characteristics and outcome of the population affected by severe pregnancy-related hypertensive disorders in the Jahun maternity ward and to identify potential risk factors for severe preeclampsia and eclampsia, including use of traditional treatment.

\section{Subjects/materials and methods Design}

In order to identify potential risk factors for severe preeclampsia/eclampsia among women in the Jahun region, we conducted a hospital-based case-control study over a 7-month period. The cases and controls were selected from the emergency obstetric program operating in the rural hospital of Jahun. All pregnant women admitted to the Jahun hospital from October 2010 to May 2011 were prospectively included in this study. Local team members interviewed patients and family members using a structured questionnaire requesting information about general demographic characteristics (maternal age, ethnicity, home village, and occupation), body mass index, blood group and Rhesus factor, hemoglobin disease, past medical history (parity, age at menarche, history of preeclampsia, pregestational hypertension/diabetes, family history of hypertension/preeclampsia), social history (literacy level, level of education, household details, baby's father's occupation), present history (current gestation details, clinical examination, available biological tests), use of traditional treatments, delivery details and neonatal outcome. Patients who visited the Jahun maternity ward and were diagnosed with severe preeclampsia and/or eclampsia during the study period were identified as cases. During the same period, women with normal pregnancy attending the Jahun maternity ward were identified as controls. For the purposes of the study, traditional treatments included herbal medicines either obtained from the wild in the crude form or as refined forms, such as concentrated extracts, teas, tinctures, or decoctions. Among others, the herbal medicines used during pregnancy in the study community included "saiwan goruba," to treat bleeding; "chediya," "taura," and "sabara," to ease abdominal pain; and "meleduwa," administered for rupture of the amniotic sac (the herbs are named after their local names).

\section{Definition of preeclampsia and eclampsia}

Eclampsia was defined as occurrence of seizure and/or altered level of consciousness not caused by epilepsy or other convulsive disorders, with signs of severe preeclampsia. Severe preeclampsia was defined as new hypertension with blood pressure of $160 \mathrm{mmHg}$ systolic or diastolic blood pressure of $110 \mathrm{mmHg}$, or greater, arising after 20 weeks of gestation in a woman who was normotensive before 20 weeks gestation, associated with proteinuria. Proteinuria was defined as a finding of $2+$ or more protein on urine dipstick. Women with $1+$ protein on urine dipstick were excluded in order to limit misclassification bias.

\section{Definition of neonatal death}

Neonatal death was defined as "a disease or injury which initiated the train of morbid events leading directly to death" within the first 28 days of life. The primary causes of neonatal death were broadly grouped under four major headings: (1) birth asphyxia, (2) sepsis (pneumonia, septicemia, and meningitis), (3) prematurity, and (4) other.

Data were analyzed using STATA Statistical Software: Release 11 (StataCorp LP College Station, TX, USA). The median and range were used for quantitative variables that were not normally distributed, and mean and $95 \%$ confidence intervals (CI) were used for normally distributed variables. 
Categorical variables were tabulated using frequencies and percentages. The Chi-square test was used for testing the significance of associations between categorical variables. Group differences were tested using the unpaired Student's $t$-test in cases of normal distribution and the nonparametric Mann-Whitney $U$-test in cases of skewed distribution. Crude and adjusted odds ratios (OR) and 95\% CI were calculated. Multiple logistic regression models were constructed to identify independent factors associated with severe preeclampsia/ eclampsia. Initial regression models were first constructed including all variables for which (1) the $P$-value (for the OR) was less than 0.05 , and (2) the OR was more than 1.1 or less than 0.90 in the univariate analysis. If two or more factors were highly correlated, only the most plausible one (from the literature) or the one with the fewest missing values was included in the model. To simplify the model, variables were removed one at a time depending on the significance test $(P<0.05)$ by the likelihood ratio test.

\section{Results}

During the study period, a total of 2,835 pregnant women were admitted to the Jahun hospital. Among them, 1,257 (44\%) were recorded as having a normal pregnancy, and 419 $(16 \%)$ women had severe preeclampsia/eclampsia (175 with severe preeclampsia and 244 with eclampsia). Among the eclamptic patients, 194 were antepartum and intrapartum, and 50 were admitted with postpartum eclampsia after a vaginal delivery at home. The sociodemographic, obstetric, and antenatal characteristics of all participants are shown in Table 1. No significant differences were observed between cases and controls with regard to geographical area of origin or referral health centre, source of admission, time to reach hospital, or ethnicity. The cases were younger (mean age 21 years; 95\% CI: 21-23) than the controls (mean age 25 years; 95\% CI: 24-26) $(P<0.001)$. The mean gestational age at delivery was not significantly different between the two groups. The proportion of cases (79\%) with fewer than four antenatal clinic visits was significantly higher than controls $(73 \%)$, by univariate analysis only. Eleven percent of eclamptic patients experienced no signs of severe hypertension, such as headache or visual changes.

A majority of women delivered at the Médecins Sans Frontières [Doctors Without Borders] hospital (75\%) and used traditional treatments during their pregnancy (63\%). The proportion of cesarean sections was significantly higher among cases $(7 \%)$ than in controls $(0 \%)$. The mean hospital length of stay was significantly longer among cases (4 days) compared with controls ( 1 day) $(P<0.001)$. Out of 419
Table I General characteristics of cases and controls admitted to the Jahun hospital maternity ward, October 20I0-May 20I I

\begin{tabular}{|c|c|c|c|}
\hline Variables & $\begin{array}{l}\text { Cases } \\
n=419\end{array}$ & $\begin{array}{l}\text { Controls } \\
n=1257\end{array}$ & $P$-value \\
\hline $\begin{array}{l}\text { Mean maternal age (years) } \\
(95 \% \mathrm{Cl})\end{array}$ & $2 I(2 I-22)$ & $25(24-26)$ & $<0.001$ \\
\hline \multicolumn{4}{|l|}{ Geographical area (\%) } \\
\hline Jahun & $201(48)$ & $679(54)$ & 0.19 \\
\hline Miga & II $3(27)$ & $289(23)$ & \\
\hline Other & $105(25)$ & $289(23)$ & \\
\hline \multicolumn{4}{|l|}{ Source of admission (\%) } \\
\hline Self admission & $369(88)$ & || $3 \mid(90)$ & \\
\hline Traditional birth attendant & $8(2)$ & $38(3)$ & \\
\hline Health center & $34(8)$ & $76(6)$ & \\
\hline Ministry of health hospital & $8(2)$ & $12(1)$ & \\
\hline $\begin{array}{l}\text { Mean time to reach } \\
\text { hospital (hours) }(95 \% \mathrm{Cl})\end{array}$ & $1.5(1.4-1.6)$ & I.4 (I.3-I.5) & 0.93 \\
\hline \multicolumn{4}{|l|}{ Ethnicity (\%) } \\
\hline Hausa & $402(96)$ & $1169(93)$ & \\
\hline Fulani & $17(4)$ & $75(6)$ & \\
\hline Other & 0 & $13(1)$ & \\
\hline $\begin{array}{l}\text { Patient's occupation as } \\
\text { housewife }\end{array}$ & $350(87)$ & $873(74)$ & $<0.001$ \\
\hline \multicolumn{4}{|l|}{ School attendance } \\
\hline None & $298(93)$ & $1085(86)$ & 0.001 \\
\hline Primary & $8(2)$ & $58(5)$ & \\
\hline Secondary & $14(4)$ & $95(7)$ & \\
\hline University & I (0) & $22(2)$ & \\
\hline Mother able to read & $17(4)$ & $104(9)$ & 0.003 \\
\hline $\begin{array}{l}\text { Number of household } \\
\text { members } \geq 3\end{array}$ & $161(52)$ & $837(7 I)$ & $<0.001$ \\
\hline $\begin{array}{l}\text { Mean number of ANC } \\
\text { visits }(95 \% \mathrm{Cl})\end{array}$ & $I(0-I)$ & $2(2-3)$ & $<0.001$ \\
\hline
\end{tabular}

Abbreviations: ANC, antenatal care; $\mathrm{Cl}$, confidence interval.

cases, ten patients died (mortality of $2.4 \%$ ). One death only was attributable to eclampsia.

The stillbirth rate was significantly higher among cases (11\%) compared with controls $(7 \%)(P=0.001)$. The neonatal outcome was similar in both groups. Table 2 shows the delivery characteristics and outcome details of the cases and controls.

Referring to Table 3, the significant variables included in the final model were age, school attendance, occupation, parity, number of household members, personal history of preeclampsia/eclampsia or hypertension, family history of preeclampsia/eclampsia or hypertension, number of antenatal clinic visits, and use of traditional treatment during pregnancy.

After adjusting for the effect of the other variables in the model, the risk factors found to be associated with a greater risk of severe preeclampsia/eclampsia included personal history of preeclampsia $(\mathrm{OR}=21.5 ; P<0.001)$, personal history of preexisting hypertension $(\mathrm{OR}=10.5 ; P<0.001)$, 
Table 2 Delivery and outcome of cases and controls at the Jahun hospital maternity ward, October 2010-May 2011

\begin{tabular}{|c|c|c|c|}
\hline Variables & $\begin{array}{l}\text { Cases } \\
n=419\end{array}$ & $\begin{array}{l}\text { Controls } \\
n=1257\end{array}$ & $P$-value \\
\hline \multicolumn{4}{|l|}{ Place of delivery $n(\%)$} \\
\hline Home/health center & $50(12) / 0(0)$ & $8(I) / I(0)$ & \\
\hline MSF & $338(8 I)$ & $1183(94)$ & \\
\hline Cesarean & $28(7)$ & $6(0)$ & $<0.001$ \\
\hline $\begin{array}{l}\text { Mean duration of hospital } \\
\text { stay (days) }\end{array}$ & 4 & 1.2 & $<0.001$ \\
\hline \multicolumn{4}{|l|}{ Perinatal outcome n (\%) } \\
\hline Stillbirth & $48(\mathrm{II})$ & $17(1)$ & $<0.001$ \\
\hline Neonatal death & $36(9)$ & $28(2)$ & $<0.001$ \\
\hline
\end{tabular}

Abbreviation: MSF, Médecins Sans Frontières.

primiparity $(\mathrm{OR}=2.5 ; P=0.001)$, occupation as a housewife $(\mathrm{OR}=1.9 ; P=0.008)$ and fewer than four antenatal clinic visits $(\mathrm{OR}=1.6 ; P=0.02)$. The use of traditional treatments during pregnancy was associated with a higher risk of developing severe preeclampsia/eclampsia $(\mathrm{OR}=1.6$; 95\% CI: 1.2-2.1), by univariate analysis only. Similarly, the protective effect of older maternal age, higher number of household members, and school attendance disappeared in the multivariate analysis.

\section{Discussion}

The results of this study are consistent with the usual risk factors for severe pregnancy-related hypertensive disorders, including primiparity and personal history of hypertensive disorders. As expected, low socioeducational status (assessed by school attendance and patient's occupation) appears to be strongly associated with preeclampsia/eclampsia.

Interestingly, the proportion of eclampsia was greater than the proportion of severe preeclampsia. Although time to referral and delay in hospitalization were not measured, it is very likely that those parameters would have been identified as risk factors for developing eclampsia. About one-half of the patients admitted to the hospital for eclampsia had antepartum preeclampsia, similar to what has been reported in other studies carried out in Nigeria. ${ }^{10-13}$ While it is clear that good antenatal care will reduce the incidence of eclampsia, it has been reported that less than $20 \%$ of eclamptic cases were preventable, in studies performed in the USA ${ }^{14}$ and in Sweden. ${ }^{15}$

Usage of traditional herbal treatments before or during the pregnancy was not found to be associated with developing severe preeclampsia/eclampsia. Herbal drug preparations were found to be very popular among the women included in this study, as is usually the case in other parts of Nigeria. ${ }^{5-7}$ Although the reasons for use were not formally recorded, reduction of nausea and vomiting associated with early pregnancy was repeatedly mentioned. Additionally, cure of specific symptoms, such as abdominal pain, jaundice, or edema were noted. Although these herbal drugs are readily available and cheap, there is a lack of specific dose and lack of information about their side effects and their safety during pregnancy. Without pharmacological data, we cannot exclude toxicity from the traditional medicines used in the study population. Hence, our reassuring finding regarding the absence of association between eclampsia and traditional treatments needs to be confirmed. It is also possible that use of traditional medicines, which increases the delay before consulting a health center, is simply a marker for harmful behavior.

\section{Limitations}

This study has several limitations. First, the hospital-based approach includes only women attending the hospital; as many women and neonates die in rural Africa without pre-

Table 3 Factors associated with severe preeclampsia and eclampsia in patients admitted at the Jahun hospital maternity ward, unadjusted and adjusted for potential confounding factors

\begin{tabular}{|c|c|c|c|c|c|}
\hline Variables & Cases, n (\%) & Controls, n (\%) & $\begin{array}{l}\text { Unadjusted OR } \\
(95 \% \mathrm{CI})\end{array}$ & $\begin{array}{l}\text { Adjusted OR } \\
(95 \% \mathrm{CI})\end{array}$ & P-value \\
\hline Age $<20$ years & $218(52)$ & $389(31)$ & $2.4(2.0-3.1)$ & $1.2(0.7-2.1)$ & 0.44 \\
\hline School attendance & $29(7)$ & I7| (14) & $2.1(1.4-3.3)$ & $1.7(0.9-3.5)$ & 0.09 \\
\hline Occupation as housewife & $348(87)$ & I I 72 (75) & $2.3(1.7-3.2)$ & $2.0(1.2-3.3)$ & 0.004 \\
\hline Primiparity & $232(56)$ & $423(34)$ & $2.5(2.0-3.1)$ & $2.5(1.5-4.3)$ & 0.001 \\
\hline Personal history of (pre)eclampsia & $215(53)$ & $61(5)$ & $21.4(15.3-30.0)$ & $21.5(14.2-32.5)$ & $<0.001$ \\
\hline Personal history of essential hypertension & $106(26)$ & $48(4)$ & $8.7(6.0-12.8)$ & $10.5(5.8-19.0)$ & $<0.001$ \\
\hline Family history of (pre)eclampsia & $39(12)$ & $56(6)$ & $2.3(1.4-3.6)$ & $\mathrm{I} .0(0.5-2.1)$ & 0.99 \\
\hline Family history of essential hypertension & $49(16)$ & $81(8)$ & $2.0(1.3-3.0)$ & $1.2(0.6-2.3)$ & 0.59 \\
\hline Number of ANC visits $<4$ & $257(79)$ & $869(67)$ & $1.8(1.3-2.4)$ & $1.6(1.1-2.4)$ & 0.02 \\
\hline Traditional treatment during pregnancy & $28 I(72)$ & $949(62)$ & $1.6(1.2-2.1)$ & $1.4(0.9-1.9)$ & 0.09 \\
\hline
\end{tabular}

Abbreviations: $\mathrm{ANC}$, antenatal care; $\mathrm{Cl}$, confidence interval; OR, odds ratio. 
senting to a health structure, community-based studies are a better instrument for exploring mortality rates. Second, the use of traditional medicine might be associated with a more severe disease, and the (pre)eclampsia may only be the outcome of evaluating a certain group of patients. Matched pairs of women of the same age and diagnosis would provide a better study design to answer this question. Third, we did not investigate in detail the practice of herbal therapy in the study population. Once again, a community-based study would better assess traditional practices involving practitioners and herbalists. Finally, the study period was not long enough to record any seasonal trend in hypertensive disorders.

\section{Conclusion}

The rate of severe pregnancy-related hypertensive disorders in the Jahun maternity ward is very high and consistent with the findings of other studies in Northern Nigeria. The proportion of eclampsia was higher than the proportion of preeclampsia, suggesting that reducing delay of presentation might be highly beneficial. No specific risk factors for severe preeclampsia and eclampsia were identified other than the usual indicators for those disorders; a community-based study would allow us to better detail the practice of herbal therapy in this population. Perinatal death rate remains high in preeclamptic/eclamptic women.

\section{Acknowledgments}

We greatly acknowledge the Médecins Sans Frontières staff and all the dedicated Nigerian field workers and translators who assisted with this project.

\section{Disclosure}

The authors declare that they have no conflicts of interest in this work.

\section{References}

1. Olatunji AO, Sule-Odu AO. Maternal mortality at Sagamu, Nigeria - a ten year review (1988-1997). Niger Postgrad Med J. 2001;8(1):12-15.

2. Okaro JM, Umezulike AC, Onah HE, Chukwuali LI, Ezugwu OF, Nweke PC. Maternal mortality at the University of Nigeria Teaching Hospital, Enugu, before and after Kenya. Afr J Reprod Health. 2001;5(2):90-97.

3. Okusanya BO, Aigere EO, Abe A, Ibrahim HM, Salawu RA. Maternal deaths: initial report of an on-going monitoring of maternal deaths at the Federal Medical Centre Katsina, Northwest Nigeria. J Matern Fetal Neonatal Med. 2013;26(9):885-888.

4. Weindling AM. The confidential enquiry into maternal and child health (CEMACH). Arch Dis Child. 2003;88(12):1034-1037.

5. Fakeye TO, Adisa R, Musa IE. Attitude and use of herbal medicines among pregnant women in Nigeria. BMC Complement Altern Med. 2009;9:53.

6. Ologe MO, Aboyeji AP, Ijaiya MA, Adesina KT, Adewara AA, Olarinoye JK. Herbal use among pregnant mothers in Ilorin, Kwra State, Nigeria. J Obstet Gynaecol. 2008;28(7):720-721.

7. Gharoro EP, Igbafe AA. Pattern of drug use amongst antenatal patients in Benin City, Nigeria. Med Sci Monit. 2000;6(1):84-87.

8. Bello FA, Morhason-Bello IO, Olayemi O, Adekunle AO. Patterns and predictors of self-medication amongst antenatal clients in Ibadan, Nigeria. Niger Med J. 2011;52(3):153-157.

9. World Health Organization. WHO recommendations for prevention and treatment of pre-eclampsia and eclampsia;2011. Available from: http://whqlibdoc.who.int/publications/2011/9789241548335_eng.pdf. Accessed July 20, 2013.

10. Onwuhafua PI, Onwuhafua A, Adze J, Mairami Z. Eclampsia in Kaduna State of Nigeria - a proposal for a better outcome. Niger $J$ Med. 2001;10(2):81-84.

11. Ikechebelu JI, Okoli CC. Review of eclampsia at the Nnamdi Azikiwe University teaching hospital, Nnewi (January 1996-December 2000). J Obstet Gynaecol. 2002;22(3):287-290.

12. El-Nafaty AU, Melah GS, Massa AA, Audu BM, Nelda M. The analysis of eclamptic morbidity and mortality in the Specialist Hospital Gombe, Nigeria. J Obstet Gynaecol. 2004;24(2):142-147.

13. Okafor UV, Efetie RE. Critical care management of eclamptics: challenges in an African setting. Trop Doct. 2008;38(1):11-13.

14. Katz VL, Farmer R, Kuller JA. Preeclampsia into eclampsia: toward a new paradigm. Am J Obstet Gynecol. 2000;182(6):1389-1396.

15. Rugarn O, Carling Moen S, Berg G. Eclampsia at a tertiary hospital 1973-1999. Acta Obstet Gynecol Scand. 2004;83(3):240-245.
International Journal of Women's Health

\section{Publish your work in this journal}

The International Journal of Women's Health is an international, peerreviewed open-access journal publishing original research, reports, editorials, reviews and commentaries on all aspects of women's healthcare including gynecology, obstetrics, and breast cancer. The manuscript management system is completely online and includes

\section{Dovepress}

a very quick and fair peer-review system, which is all easy to use. Visit http://www.dovepress.com/testimonials.php to read real quotes from published authors. 